\title{
Podstawy metody wyznaczania parametrów energooszczędnej jazdy pojazdów trakcyjnych na obszarach aglomeracyjnych
}

\begin{abstract}
W artykule przedstawiono autorski pomyst na sposób wyznaczania parametrów sterowania prędkościa pasażerskiego pojazdu trakcyjnego podczas przejazdu trasy wieloodcinkowej realizowanego z założonq sumq czasów jazdy na poszczególnych odcinkach, co przektada się na zadanie opracowania metody takiego sterowania prędkościa, by przejazd trasy $w$ zadanym tacznym czasie odbyt się z minimalnym poborem energii
\end{abstract}

\section{Wprowadzenie}

Współczesne pojazdy trakcyjne wyposażone są w różnorakie systemy komputerowe, których możliwości obliczeniowe i szybkość działania z punktu widzenia sterowania pojazdem są nie wykorzystane, a które pozwalają $\mathrm{m}$. in. realizować jazdę ze stałą prędkością (tzw. tempomaty, UPZ), niezależnie od obciążenia pasażerami, profilu toru i innych mniej istotnych czynników. Jeśli do tego dodać możliwości jakie daje nowoczesny napęd trakcyjny sterowany impulsowo, to watro zastanowić się nad zasadą doboru parametrów jazdy pojazdów trakcyjnych przewożących pasażerów w obszarach aglomeracyjnych. Przewozy te odbywają się z reguły na wydzielonych trasach (wydzielone linie tramwajowe, metro, wydzielone koleje aglomeracyjne, np. WKD, SKM), na których ruch odbywa się płynnie, bez wpływu systemów zewnętrznych.

Dostępne publikacje na temat energetycznie oszczędnych jazd dotyczą zasadniczo $[1,2,3,4]$ :

- wyznaczania charakterystyk i mocy pojazdów trakcyjnych

- wyznaczania parametrów sterowania dla przyjętego czasu przejazdu zadanego odcinka trasy

- wykorzystania energii kinetycznej pojazdu. i w odniesieniu do sterowania prędkością jazdy na trasach wieloodcinkowych podają tylko ogólne wskazania.

W artykule przedstawiono autorski pomysł na sposób wyznaczania parametrów sterowania prędkością pasażerskiego pojazdu trakcyjnego podczas przejazdu trasy wieloodcinkowej realizowanego z założoną sumą czasów jazdy na poszczególnych odcinkach, co przekłada się na zadanie opracowania metody takiego sterowania prędkością, by przejazd trasy $\mathrm{w}$ zadanym łącznym czasie odbył się z minimalnym poborem energii.

Metoda oparta jest na badaniu przebiegu charakterystyk zużycia energii $w$ funkcji czasu przejazdu $E=f(t)$ dla wszystkich odcinków trasy i wymaga porównania ze sobą charakterystyk zużycia energii wyznaczonych dla wszystkich odcinków.
Metoda ta może być wykorzystywania nie tylko do wyznaczania parametrów standardowego przejazdu, odbywającego się bez zakłóceń wewnętrznych, lecz także do przejazdu zakłóconego (np. dłuższym niż planowane zatrzymaniem na przystanku), gdzie odrobienie opóźnienia wymaga forsowniejszej jazdy na odcinkach wyznaczanych on-line tak, by to odrabianie zaległości odbywało się kosztem minimalnej dodatkowej energii. Możliwość takiego sterowania prędkością zapewnia dzisiaj wyposażenie techniczne zainstalowane na nowoczesnych szynowych pojazdach trakcyjnych.

\section{Parametry wpływające na charakterystykę zużycia energii}

Dla eksperymentalnie wybranego zadanego czasu przejazdu odcinka typowego dla ruchu w aglomeracjach, energetycznie optymalny jest przejazd w sekwencji: rozruch, jazda z prędkością ustalona, wybieg i hamowanie, a dla odcinków krótszych nawet bez fazy jazdy z prędkością ustaloną.

Zarówno rozruch jak i hamowanie powinny być realizowane z maksymalną mocą układu rozruchowego i hamowania, a czas pracy silników trakcyjnych (poboru i zwrotu energii) powinien być tak dobrany, by maksymalnie wykorzystać moc ciągłą silników trakcyjnych.

Jak wspomniano we wstępie podstawowym elementem analizy są charakterystyki zużycia energii przez pojazd, uwzględniając odzysk energii w fazie hamowania.

Przebieg charakterystyki $E=f(t)$ dla określonego odcinka trasy dla danego typu pojazdu trakcyjnego zależy podstawowo od następujących czynników:

a) charakterystyki trakcyjnej (opartej na parametrach napędu elektrycznego (silnik, przekształtnik, przekładnia)

b) charakterystyki hamowania, w tym odzyskowego 
c) obciążenia pojazdu (masy pasażerów)

d) napięcia sieci (w przypadku, gdy napięcie spada poniżej minimalnego dla znamionowej pracy przekształtnika)

e) sposobu jazdy (proporcji między czasami realizowania faz rozruchu, stałej prędkości, wybiegu i hamowania).

W przypadku powtarzalnych warunków eksploatacji (zapełnienia pasażerami, czasu wymiany pasażerów na przystanku, warunków zasilania na odcinkach między podstacjami, itp.) dla przebiegu charakterystyki $\mathrm{E}=$ $\mathrm{f}(\mathrm{t}) \mathrm{z}$ punktu widzenia prezentowanej metody istotne są czynniki wg pkt a), b) i d). Można zatem przyjąć, że dla pojazdów obsługujących systemy komunikacji masowej w aglomeracjach, czyli jak wymieniono wcześniej tramwajów na wydzielonych trasach, metra, zespołów trakcyjnych na wydzielonych liniach, zdecydowana większość przejazdów odbywa się według stałych, łatwych do wyznaczenia charakterystyk zużycia energii dla kolejnych odcinków trasy.

Wynika $\mathrm{z}$ tego zasadność zastosowania modelu zużycia energii $w$ postaci krzywych $E=f(t)$ dla uzyskania założonego celu racjonalizowania zużycia energii podczas przejazdu trasy wieloodcinkowej w wyznaczonym czasie.

\section{Opis metody}

Najogólniej mówiąc metoda polega na skorygowaniu intuicyjnie przyjętych zadanych czasów przejazdu $t_{z n}$ kolejnych n- odcinków międzyprzystankowych tak, aby suma wydłużeń czasów przejazdów, co powoduje równocześnie zmniejszanie poboru energii o $\Delta \mathrm{E}_{1}$, była równa sumie skróceń czasów przejazdów pozostałych odcinków (co wiąże się ze zwiększeniem poboru energii o $\Delta \mathrm{E}_{2}$ ).

Czas zadany $\mathrm{t}_{\mathrm{z}}$ dla danego kolejnego odcinka należy do zbioru:

gdzie:

$$
t_{z}=\left\{\mathrm{t}_{\min }, \ldots \ldots, \mathrm{t}_{\mathrm{o}}, \ldots \ldots, \mathrm{t}_{\max }\right\}
$$

- $\mathrm{t}_{\min }$ - najkrótszy z możliwych czasów przejazdu odcinka, jazda forsowna)

- $t_{o}$ - czas przejazdu optymalnego wyznaczony opisywaną metodą

- $\mathrm{t}_{\max }$ - najdłuższy z możliwych czasów przejazdu odcinka, jazda z maksymalnym wybiegiem.

Wydłużanie czasu przejazdu (przejazd z mniejszym udziałem jazdy pod prądem) będzie odbywało się na odcinkach trasy, dla których stromość charakterystyki $E=f(t)$, czyli jej pochodna $w$ punkcie $t_{z}$ jest duża, a skracanie czasów przejazdu będzie odbywało się na odcinkach trasy, dla których jej pochodna $\mathrm{w}$ punkcie $\mathrm{t}_{\mathrm{z}}$ jest mała.

Dla celów opracowania metody posłużono się parametrami trasy planowanej dla LST.

Na rys. 1 przedstawiono przykładowe krzywe dla odcinka z najbardziej stromą charakterystyką zużycia energii (a) oraz dla odcinka $z$ charakterystyką najłagodniejszą (b) dla ww. trasy.

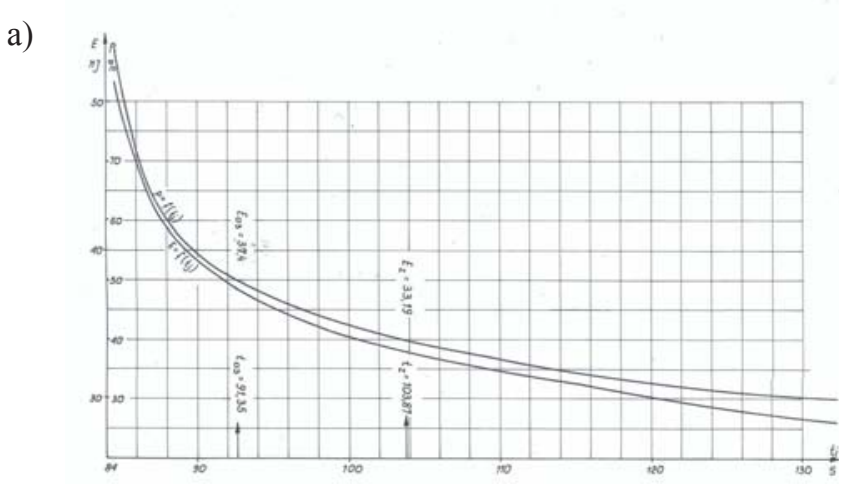

b)

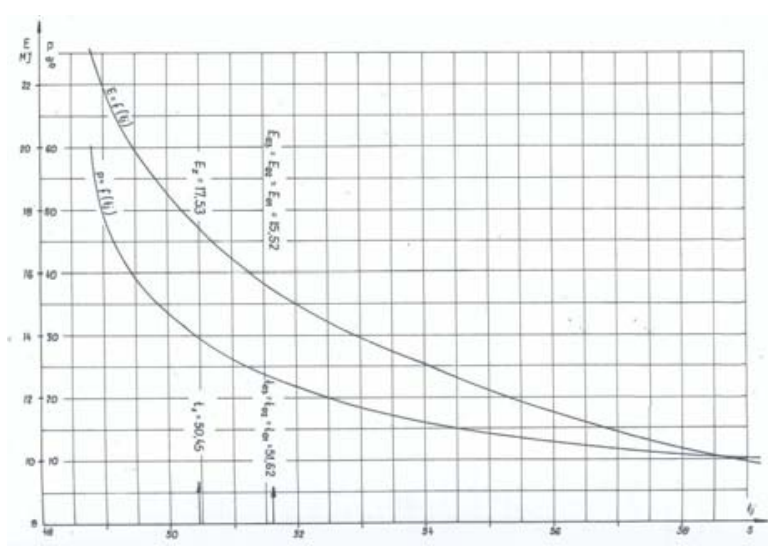

Rys. 1. Charakterystyki zużycia energii i procentu jazdy drogi pod prądem w funkcji czasu dla wybranych odcinków trasy

Na rys. 2. przedstawiono graficzną ilustrację metody wyznaczania optymalnych czasów przejazdu, przykładowo dla dwóch odcinków międzyprzystankowych. Zależności między opisanymi na wykresie wielkościami są następujące:

$$
\begin{array}{ll}
> & \Delta \mathrm{t}_{1}=\Delta \mathrm{t}_{2} \\
> & \left(\frac{d E}{d t}\right)_{t z 1}>\left(\frac{d E}{d t}\right)_{t z 2} \\
> & \left(\frac{d E}{d t}\right)_{t o 1}=\left(\frac{d E}{d t}\right)_{t o 2}
\end{array}
$$

W ten sposób zostanie uzyskany efekt zmniejszenia poboru energii z sieci, ponieważ przy takim postępowaniu $\Delta \mathrm{E}_{1}>\Delta \mathrm{E}_{2}$.

Dla znalezienia parametrów jazdy na wszystkich odcinkach trasy, w celu wydłużenia lub skrócenia czasu przejazdu kolejnych odcinków, dla zmniejszenia poboru energii, konieczne jest wykreślenie dwóch krzywych: $\Delta \mathrm{E}_{1}=\mathrm{f}(\mathrm{t})$ i $\Delta \mathrm{E}_{1}=\mathrm{f}(\mathrm{t})$.

Pierwsza z nich będzie zbiorem części charakterystyk $\mathrm{E}=\mathrm{f}(\mathrm{t})$ uporządkowanych wg wartości pochodnych $\left(\frac{d E}{d t}\right)$ w otoczeniu zadanego intuicyjnie czasu jazdy $\mathrm{t}_{\mathrm{z}}$ w kolejności od pochodnych największych do najmniejszych. Druga krzywa będzie zbiorem części cha- 


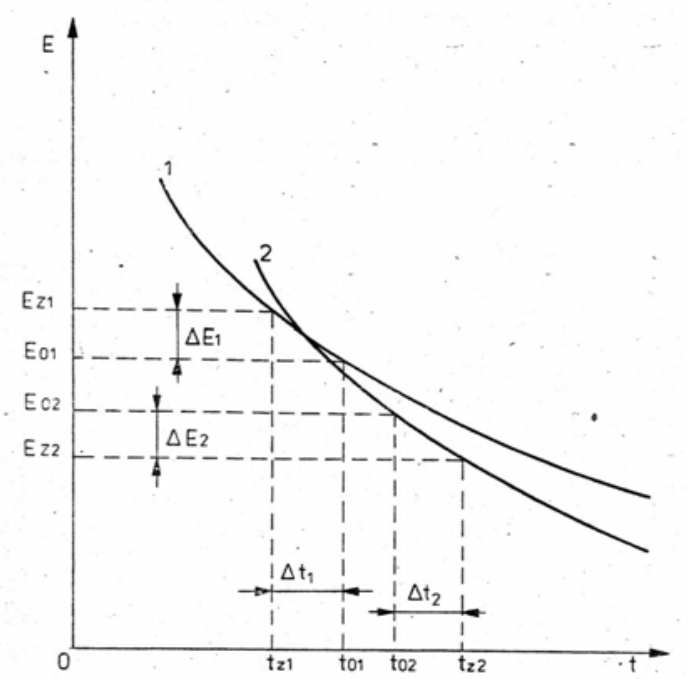

Rys. 2. Ilustracja graficzna metody wyznaczania czasów przejazdu dwóch odcinków

$t_{z}$ - czas zadany, $E_{z}$ - energia pobrana podczas przejazdu z czasem $t_{z}$, indeks ${ }_{1}$ dla odcinka 1,' analogicznie ${ }_{2}$ dla 2.

rakterystyk $E=f(t)$, ale uporządkowanych $w$ kolejności odwrotnej.

Praktyczne zastosowanie metody wymaga:

- wyznaczenia charakterystyk $E=f(t)$ dla wszystkich odcinków międzyprzystankowych

- „wczytania przebiegu” tych charakterystyk w postaci cyfrowej (po zastosowaniu odpowiedniej aproksymacji)

- przesortowania charakterystyk wg wartości pochodnych dla zadanych czasów jazdy

- wyznaczenia czasów optymalnych

- $\quad$ wyznaczenia czasów optymalnych $t=t_{0}$, dla których wartości pochodnych charakterystyk następnych $(i+1)$ są równe pochodnym dla czasów $\mathrm{t}=\mathrm{t}_{\mathrm{z}}$ charakterystyk poprzednich (i). Wyraża to zależność:

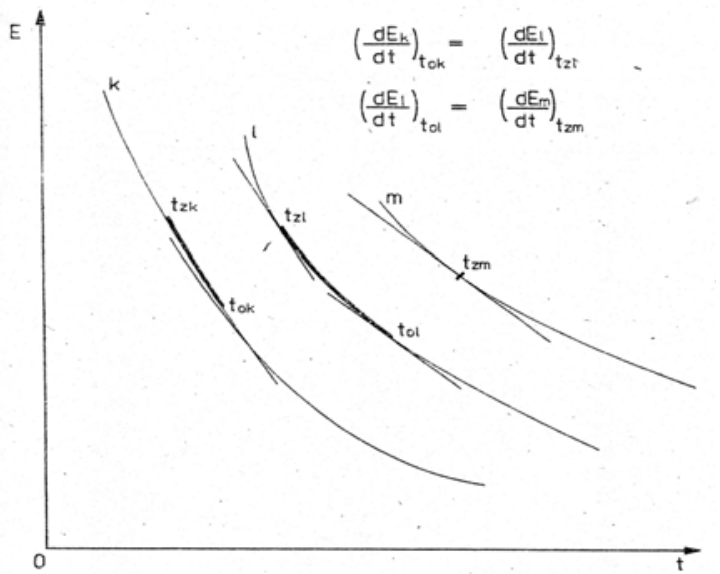

Rys. 3. Składanie charakterystyki $\Delta \mathrm{E}=\mathrm{f}(\mathrm{t})$

$\left(k, l, m\right.$-indeksy kolejnych charakterystyk, $t_{z}$ - czasy zadane, $t_{o}-$ czasy jazdy optymalizujacej zużycie energii)

$$
\left(\frac{d E_{i+1}}{d t}\right)_{t=t_{o}}=\left(\frac{d E_{i}}{d t}\right)_{t=t}
$$

Dotyczy to obu charakterystyk, tej składanej w kolejności od części najbardziej do najmniej stromej (zbiór 1) i drugiej tworzonej w kolejności odwrotnej (zbiór 2).

W następnej kolejności konieczne jest wykreślenie charakterystyki $\Delta \mathrm{E}_{1}=\mathrm{f}(\mathrm{t})$ wyznaczonej ze zbioru pierwszego i $\Delta \mathrm{E}_{2}=\mathrm{f}(\mathrm{t})$ ze zbioru drugiego charakterystyk.

Zasadę „składania” odcinków charakterystyk przedstawia rys. 3.

\begin{tabular}{|c|c|c|c|c|c|c|}
\hline \multirow[b]{2}{*}{$\mathrm{Nr}$} & \multirow[b]{2}{*}{ t zad [s] } & \multirow[b]{2}{*}{ t opt [s] } & \multirow{2}{*}{$\begin{array}{c}\text { E t zad } \\
\text { [MJ] }\end{array}$} & \multirow{2}{*}{$\begin{array}{c}\text { E t opt } \\
\text { [MJ] }\end{array}$} & \multicolumn{2}{|c|}{$\%$ jazdy pod pradem } \\
\hline & & & & & zad & opt \\
\hline 1 & 66,16 & \begin{tabular}{|l|}
67,49 \\
\end{tabular} & 21,53 & 20,31 & 30 & 26 \\
\hline 2 & 74,55 & 74,61 & 15,89 & 15,86 & 15 & 15 \\
\hline 3 & 64,58 & 64,75 & 20,92 & 20,67 & 30 & 28 \\
\hline 4 & 64,62 & 64,86 & 16,84 & 16,57 & 20 & 19 \\
\hline 5 & 50,45 & 51,62 & 17,53 & 15,52 & 30 & 23 \\
\hline 6 & 88,27 & 88,56 & 25,21 & 24,95 & 30 & 29 \\
\hline 7 & 78,91 & 76,21 & 23,73 & 25,12 & 30 & 33 \\
\hline 8 & 61,59 & 62,01 & 20,35 & 19,78 & 30 & 28 \\
\hline 9 & 53,89 & 54,10 & 14,74 & 14,49 & 20 & 19 \\
\hline 10 & 44,99 & 45,51 & 12,83 & 12,17 & 20 & 18 \\
\hline 11 & 98,61 & 100,59 & 27,45 & 26,27 & 30 & 26 \\
\hline 12 & 103,87 & 91,35 & 33,13 & 38,00 & 40 & 50 \\
\hline 13 & 71,37 & 71,98 & 22,37 & 21,48 & 30 & 28 \\
\hline 14 & 48,80 & 49,05 & 17,45 & 17,12 & 30 & 27 \\
\hline 15 & 78,88 & 80,97 & 23,97 & 22,88 & 30 & 27 \\
\hline 16 & 70,22 & 71,12 & 22,31 & 21,79 & 30 & 28 \\
\hline 17 & 66,43 & 69,51 & 25,95 & 23,66 & 40 & 33 \\
\hline 18 & 67,39 & 67,61 & 21,72 & 21,45 & 30 & 28 \\
\hline 19 & 66,04 & 67,18 & 17,04 & 15,70 & 20 & 16 \\
\hline 20 & 46,02 & 46,55 & 16,87 & 16,32 & 30 & 28 \\
\hline suma & 1365,64 & 1365,64 & 417,83 & 410,11 & $\Delta \mathbf{E}_{\mathrm{m}}=$ & $2 \mathrm{MJ}$ \\
\hline
\end{tabular}

Tablica 1

Parametry jazdy kolejnych odcinków trasy 


\begin{tabular}{|c|c|c|c|c|c|c|c|c|c|}
\hline $\mathrm{Nr}$ & dE (MJ) & dt (s) & $\mathrm{dE} / \mathrm{dt}$ & $t$ min & t zad & t opt & $t \max$ & sum t & sum E \\
\hline 5 & $-1,910$ & 1,090 & $-1,752$ & 48,78 & 50,45 & 51,54 & 56,00 & 1,09 & $-1,91$ \\
\hline 3 & $-0,260$ & 0,180 & $-1,444$ & 63,07 & 64,58 & 64,76 & 72,07 & 1,27 & $-2,17$ \\
\hline 13 & $-0,962$ & 0,680 & $-1,415$ & 70,40 & 71,37 & 72,05 & 74,75 & 1,95 & $-3,13$ \\
\hline 8 & $-0,260$ & 0,185 & $-1,405$ & 59,16 & 61,59 & 61,77 & 64,75 & 2,14 & $-3,39$ \\
\hline 2 & $-0,027$ & 0,020 & $-1,350$ & 73,30 & 74,55 & 74,57 & 77,14 & 2,16 & $-3,42$ \\
\hline 14 & $-0,180$ & 0,135 & $-1,333$ & 46,30 & 48,80 & 48,93 & 51,86 & 2,29 & $-3,60$ \\
\hline 10 & $-0,550$ & 0,430 & $-1,279$ & 42,77 & 44,99 & 45,42 & 51,17 & 2,72 & $-4,15$ \\
\hline 9 & $-0,125$ & 0,100 & $-1,250$ & 50,70 & 53,89 & 53,99 & 59,37 & 2,82 & $-4,27$ \\
\hline 18 & $-0,119$ & 0,100 & $-1,190$ & 64,40 & 67,39 & 67,49 & 71,44 & 2,92 & $-4,39$ \\
\hline 19 & $-1,110$ & 0,937 & $-1,185$ & 64,00 & 66,04 & 66,97 & 71,52 & 3,86 & $-5,50$ \\
\hline 4 & $-0,280$ & 0,252 & $-1,111$ & 60,75 & 64,62 & 64,87 & 71,14 & 4,11 & $-5,78$ \\
\hline 20 & $-0,400$ & 0,380 & $-1,053$ & 43,26 & 46,02 & 46,40 & 49,33 & 4,49 & $-6,18$ \\
\hline 1 & $-0,560$ & 0,580 & $-0,966$ & 62,09 & 66,16 & 66,74 & 70,94 & 5,07 & $-6,74$ \\
\hline 6 & $-0,170$ & 0,180 & $-0,944$ & 86,29 & 88,27 & 88,45 & 98,40 & 5,25 & $-6,91$ \\
\hline 17 & $-2,140$ & 2,850 & $-0,751$ & 62,30 & 66,43 & 69,28 & 71,90 & 8,10 & $-9,05$ \\
\hline 11 & $-0,540$ & 0,860 & $-0,628$ & 93,00 & 98,61 & 99,47 & 115,00 & 8,96 & $-9,59$ \\
\hline 16 & $-0,430$ & 0,750 & $-0,573$ & 61,90 & 70,22 & 70,97 & 79,90 & 9,71 & $-10,02$ \\
\hline 15 & $-0,680$ & 1,270 & $-0,535$ & 69,74 & 78,88 & 80,15 & 87,72 & 10,98 & $-10,70$ \\
\hline 7 & $-2,625$ & 6,560 & $-0,400$ & 67,90 & 78,91 & 86,77 & 98,44 & 17,54 & $-13,33$ \\
\hline 12 & $-4,570$ & 12,520 & $-0,365$ & 86,55 & 103,87 & 91,35 & 135,00 & 30,06 & $-17,90$ \\
\hline
\end{tabular}

Tablica 2

Parametry jazdy 20-odcinkowej trasy po optymalizacji
$\mathrm{Na}$ podstawie danych $\mathrm{z}$ tablicy 2 wykreślono dwie krzywe przedstawione na rys. 4 .

\section{Przykladowe zastosowanie}

Opisane wyżej założenia metody zostały zastosowane do planowanej 20- odcinkowej trasy w aglomeracji lubelskiej dla teoretycznego pojazdu trakcyjnego o parametrach typowych dla obsługi takiego ruchu.

Parametry przejazdu tej trasy dla kolejnych odcinków zestawione zostały w tablicy 1 , a w tablicy 2 zestawione zostały parametry jazdy w kolejności od największej pochodnej energii względem czasu $\mathrm{w}$ otoczeniu czasów zadanych.

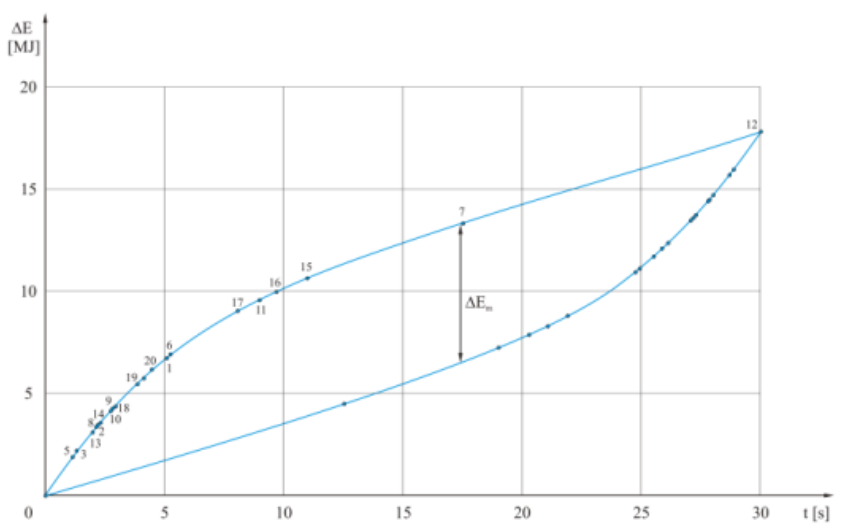

Rys. 4. Charakterystyki optymalizujące pobór energii

Pozwalają one wyznaczyć maksymalną różnicę $\Delta \mathrm{E}_{\mathrm{m}}$ między wartościami $\Delta \mathrm{E}_{1}$ i $\Delta \mathrm{E}_{2}$, która jest efektywną oszczędnością energii uzyskaną z wydłużania czasów przejazdu jednych odcinków (wg krzywej $\Delta \mathrm{E}_{1}$ ) i skracania czasów przejazdu na innych odcinkach (wg krzywej $\Delta \mathrm{E}_{2}$ ), co można wyrazić zależnością:

$$
\Delta \mathrm{E}_{\mathrm{m}}=\Delta \mathrm{E}_{1}-\Delta \mathrm{E}_{2}>0 \text {. }
$$

\section{Podsumowanie przykładowego zastosowania}

Uzyskanie oszczędności energii na poziomie ok. 6,8 MJ można uzyskać intensyfikując jazdę na odcinkach 7 i 12, a na pozostałych jadąc $\mathrm{Z}$ mniejszym udziałem drogi pod prądem.

Podobne obliczenia zostały wykonane dla przejazdu w kierunku odwrotnym. Uzyskano oszczędność energii ok. $3 \mathrm{MJ}$ (różnica wynika z profilu pionowego trasy), co łącznie daje ok. $10 \mathrm{MJ}$.

\section{Wnioski}

- Uzyskana tą metodą oszczędność energii (ok. 10 MJ dla jazdy w obie strony, co stanowi ok. 1,3\% całkowitego zużycia) nie wygląda być może imponująco, ale należy mieć na uwadze metodę jaką tę oszczędność uzyskano. Uzyskano ją tylko dzięki odpowiedniemu skorygowaniu rutynowo ustalanych czasów przejazdów kolejnych odcinków międzyprzystankowych, zatem w sposób całkowicie beznakładowy.

- Metoda możliwa jest do zastosowania we wszystkich nowoczesnych zespołach trakcyjnych wyposażonych w komputery pokładowe stosowane do sterowania pojazdem. Konieczne jest tylko przygotowanie odpowiednich programów opracowanych na podstawie parametrów danej trasy i parametrów pojazdów obsługujących przewozy.

- Wysoką dokładność metody można uzyskać po dopracowaniu metod aproksymacji charakterystyk pojazdu i algorytmów korygujących optymalne czasy przejazdu w przypadku zakłóceń w ruchu pociagu, przekładających się na konieczność wyznaczenia on-line nowych parametrów sterowania prędkością pojazdu. 


\section{Bibliografia}

[1] Kacprzak J.: Moc uktadu napędowego pojazdu przy jeździe minimalizujacej energię. Materiały VI Sympozjum „Transport pasażerski”. Katowice 1984

[2] Kacprzak J.: Optymalizacja parametrów jazdy elektrycznych pojazdów trakcyjnych. Elektryka nr 69. Politechnika Warszawska 1982
[3] Mierzejewski L., Szelag A.: Zagadnienia racjonalizacji zużycia energii elektrycznej w systemie zelektryfikowanego transportu kolejowego. Technika Transportu Szynowego 2001 nr 5

[4] Szelag A.: Rola rozwiqzań technicznych pojazdów i sposobu ich eksploatacji w ograniczaniu zużycia energii przez pojazdy kolejowe. Seminarium ,,Techniczne, prawne i finansowe aspekty zakupów $i$ modernizacji taboru kolejowego". Warszawa, 22-23.03.2007 